\title{
Análise estrutural de vigas mistas treliçadas do tipo steel-joist warren modificada
}

\author{
Structural analysis of mixed trusses \\ beam steel joist modified \\ warren type
}

Luiz Gustavo Cruz Trindade ${ }^{1}$, Gabriela Rezende Fernandes ${ }^{1}$, Renato Bertolino Júnior ${ }^{1}$

\footnotetext{
${ }^{1}$ Departamento de Engenharia Civil - UNESP/ CEP: 15385-000, Ilha Solteira, SP e-mail: 1trindade.eng@gmail.com, gabrielar.fernandes@gmail.com,rbj@dec.feis.unesp.br
}

\begin{abstract}
RESUMO
Neste trabalho, determina-se a capacidade resistente e o modo de ruptura de uma viga mista treliçada, biapoiada, do tipo steel-joist warren modificada. Esses tipos de treliças, mistas em aço e concreto, são alternativas bastante eficientes para vencer grandes vãos, sendo geralmente empregadas em edifícios comerciais e industriais, além de pontes ferroviárias e rodoviárias. Por outro lado, em muitos casos as vigas treliçadas do tipo steel-joist [10] são indicadas a fim de possibilitar a passagem de dutos. Neste trabalho, essa viga que será adotada com vão de 13,6 metros, será analisada considerando-se três diferentes tipos de análises: i) analítica ii) numérica bi-dimensional adotando material com comportamento elástico através do software SAP2000 [9] iii) numérica tri-dimensional adotando o material com comportamento elasto-plástico, sendo as análises numéricas realizadas através do software ANSYS [2]. Todas as análises foram feitas tanto para ações permanentes, quanto para ações variáveis, sendo os resultados avaliados tendo como premissa as prescrições das normas técnicas brasileiras. $\mathrm{O}$ estudo mostrou que tanto na treliça steel-joist isolada quanto na treliça mista, as diagonais e os montantes foram pouco solicitados. Além disso, mesmo ocorrendo escoamento em alguns trechos dos apoios, foi constatada a ação mista na treliça em aço-concreto. Em todas as análises foi também verificado o estado limite de serviço, obtendo-se os maiores deslocamentos através da análise numérica.
\end{abstract}

Palavras-chave: Estruturas metálicas, treliças, steel - joist, estrutura mista.

\begin{abstract}
In this work, the failure capacity and the rupture mode of a simply supported mixed truss beam steel-joist modified warren type has been determined. The mixed steel-concrete trusses, which are very efficient to overcome large spans, are generally used in commercial and industrial buildings as well as in railway and road bridges. In many cases, in order to enable the passage of ducts, steel-joist truss beam must be considered. In this work, a span of 13.6 meters will be adopted for this truss beam for which three different analysis will be considered: i)analytical procedure ii) bi-dimensional numerical modeling by software SAP2000 [9] considering material with elastic behavior iii) three-dimensional numerical modeling considering material with elasto-plastic behavior, being the numerical analysis performed by software ANSYS [2]. For all analysis, permanent and variable actions have been considered as well as the prescriptions of the Brazilian code, being the results compared to the numerical analysis. It has been verified that for both mixed and isolated steel-joist trusses, the diagonal and amounts have presented small values for internal forces. Besides, even when regions next to the support have reached the yielding limit, the mixed action for the mixed trusses has been observed. In all the analysis the resistance load for design has been also verified, being the bigger displacements computed with the numerical modeling.
\end{abstract}

Keywords: Steel structures, trusses, steel - joist, mixed structure.

1. INTRODUÇÃO

Denomina-se sistema misto aço-concreto àquele no qual um perfil de aço (laminado, soldado ou formado a frio) trabalha em conjunto com o concreto (geralmente armado), formando um pilar misto, uma viga mista, 
uma laje mista ou uma ligação mista. A viga mista é composta por uma viga, com perfil I ou uma treliça, trabalhando em conjunto com uma laje de concreto, que pode ter forma steel-deck ou não. Entretanto, normalmente um pé-direito alto é requerido para se permitir a passagem de tubulações e dutos de grandes diâmetros através de aberturas em vigas de aço. Assim, pela necessidade de se vencer grandes vãos e pelas limitações de altura impostas a edificações de múltiplos pavimentos, novos sistemas de vigas mistas foram surgindo. Dentre aquelas que surgiram mais recentemente, podem-se citar: as vigas mistas com inércia variável, as vigas mistas com aberturas na alma, as vigas celulares mistas, as stubgirders, as steel-joists mistas e, por fim, as treliças mistas.

As treliças mistas são uma alternativa bastante eficiente para vencer grandes vãos. Geralmente são construídas com perfis tipo cantoneira, e, em grande parte dos casos, possui um painel Vierendeel central. Este tipo de painel tem como objetivo principal possibilitar a passagem de dutos, dificultada nos quadros com a presença de diagonais. Assim, neste trabalho, determina-se a capacidade resistente e o modo de ruptura de uma treliça steel-joist [10], do tipo warren modificada, bi-apoiada com 13,6 metros de vão, considerando-se: i)um procedimento de cálculo analítico ii)modelagem numérica bi-dimensional com comportamento elástico iii) modelagem numérica tri-dimensional com comportamento elasto-plástico. Esta estrutura foi projetada para diversificar o esquema de composição de uma viga mista, por apresentar perspectivas de uma eficiente solução estrutural, aliando resistência e rapidez construtiva.

\section{MATERIAIS E MÉTODOS}

Este item apresenta as características da estrutura a ser analisada, bem como os procedimentos e as principais considerações aplicadas para a análise da interação mista (treliça mista) e não mista (treliça isolada) da treliça steel-joist, a análise consistiu em 3 etapas: cálculo analítico, modelagens numéricas bidimensionais e tridimensionais.

\subsection{Características da estrutura}

A estrutura a ser analisada consiste em uma laje de concreto armado sobre uma forma de aço steel-deck, trabalhando em conjunto com uma treliça plana de aço como mostra a Figura 1. Para os banzos superior e inferior adotaram-se perfis do tipo $\mathrm{U}$ simples formado a frio e para as diagonais e montantes, perfis do tipo $2 \mathrm{~L}$ (duas cantoneiras frente a frente). O perfil U simples é caracterizado geometricamente por ter medidas: $b_{w}$ (altura da seção), $b_{f}$ (largura da mesa), $t$ (espessura), $A_{g}$ (área da seção). O perfil L tem como características geométricas: $b_{f}$ (largura das duas abas da seção), $t$ (espessura), $\mathrm{A}_{\mathrm{g}}$ (área da seção). A treliça de aço foi prédimensionada para banzos superior e inferior com perfil US250*100*6,35, que tem como medidas na seção: $b_{w}=250 \mathrm{~mm} ; b_{f}=100 \mathrm{~mm}, t=6,35 \mathrm{~mm}, A_{g}=26,96 \mathrm{~cm}^{2}$. Enquanto que as diagonais e os montantes foram prédimensionados com perfil $2 \mathrm{~L} 51 * 51 * 4,75$, sendo $b_{f}=51 \mathrm{~mm}, t=4,75 \mathrm{~mm}, A_{g}=8,79 \mathrm{~cm}^{2}$. A conexão entre a laje e o banzo superior foi feita através de conectores de cisalhamento do tipo stud bolt, sendo os nomes e números adotados para as barras mostrados na Figura 2.

Os dados da forma de aço steel-deck MF-50, com espessura nominal de $0,8 \mathrm{~mm}$, foram encontrados no catálogo da METFORM [7], tendo sido utilizada em conjunto com conectores de diâmetro de $19 \mathrm{~mm}$. A espessura total da laje é $120 \mathrm{~mm}$ e para o concreto tem-se: resistência a compressão de $25 \mathrm{Mpa}$, módulo de elasticidade de 23800MPa e coeficiente de Poisson igual a 0,2. Utilizou-se aço A36 para a treliça, com tensão de escoamento igual a $250 \mathrm{MPa}$, módulo de elasticidade $200000 \mathrm{MPa}$ e o coeficiente de Poisson igual a 0,3 . Os apoios da treliça steel-joist foram modelados para simular uma treliça bi-articulada, porém com excentricidades devido ao fato dela estar apoiada em consoles de pilares.

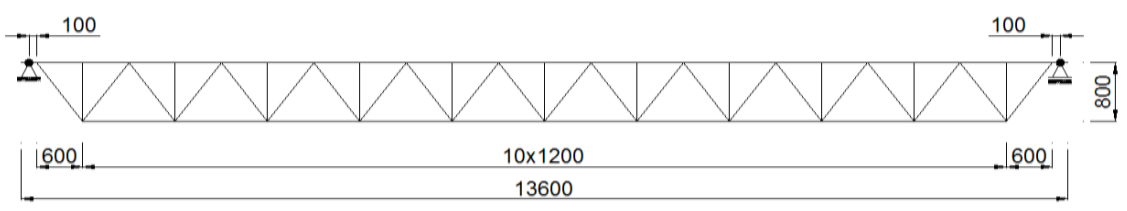

Figura 1: Dimensões da treliça steel-joist. Unidade em milímetros. 


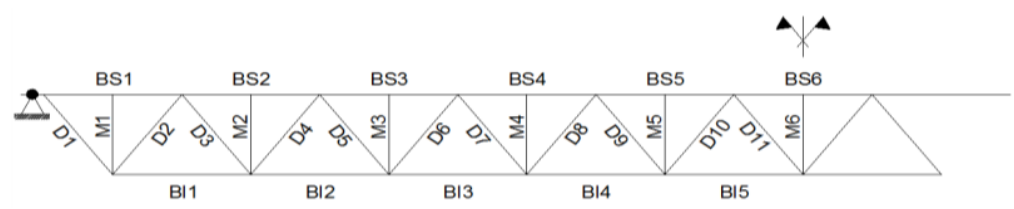

Figura 2: Definição das barras

\subsection{Resistência das barras, conectores stud-bolts para o estado limite último}

A norma canadense CSA [5], juntamente com a norma brasileira NBR 8800 [4], indicam que o dimensionamento do banzo superior deve ser feito considerando o carregamento correspondente à fase construtiva da estrutura, onde ainda não ocorre a ação mista. $\mathrm{O}$ dimensionamento do banzo inferior, diagonais e montantes deve ser feito considerando o carregamento na fase de uso e ocupação da estrutura onde ocorre a ação mista. Assim, as ações de cálculo foram obtidas através da soma de ações nominais, majoradas por coeficientes de ponderação de acordo com a norma NBR 8800 [4]. Para a treliça isolada, a ação de cálculo e o momento fletor máximo obtido no centro do vão foram, respectivamente: $7,2 \mathrm{kN} / \mathrm{m}$ e $166,5 \mathrm{kN} . \mathrm{m}$. Para a treliça mista esses valores foram os seguintes: $21 \mathrm{kN} / \mathrm{m}$ e $485,5 \mathrm{kN} . \mathrm{m}$.

No pré-dimensionamento definiu-se a seção transversal dos perfis através de cálculo analítico determinando a resistência dos perfis. A condição de segurança necessária para a treliça seria que o banzo inferior estivesse submetido à tração do momento fletor, devido à ação mista e o banzo superior estivesse submetido à compressão do momento fletor, devido à ação não mista da treliça isolada. Para o dimensionamento das diagonais e montantes foi considerado que a diagonal mais próxima do apoio estivesse tracionada e o montante mais próximo desta diagonal estivesse comprimido.

Então, o projeto manteve o espaçamento longitudinal dos conectores de cisalhamento e a resistência da laje e das juntas soldadas dentro de limites seguros, evitando assim, o aparecimento de estados limites último indesejáveis. A interação completa entre o banzo superior e a laje foi garantida pela condição de que o banzo inferior estivesse submetido às tensões de escoamento, o que o levaria ao estado limite último, que é o comportamento desejado para treliças mistas.

O cálculo do número necessário de conectores foi realizado de acordo com a norma NBR 8800 [4], obtendo-se 11 conectores, de $19 \mathrm{~mm}$ de diâmetro, de cada lado da treliça, espaçados a cada $600 \mathrm{~mm}$ e coincidindo com os nós do banzo superior.

Considerando-se que a resistência das soldas é maior que aquela dos perfis, e, assumindo-se que as soldas sejam bem executadas, foi adotada a hipótese de que elas não criam um estado limite.

\subsection{Deslocamento Vertical Máximo}

O deslocamento vertical máximo imediato, $\delta_{\max }$, de uma treliça mista bi-apoiada submetida a um carregamento distribuído pode ser calculado pela Equação 01, determinado pela teoria básica da resistência dos materiais, onde $L$ é o comprimento do vão da treliça, $E$ é o módulo de elasticidade do aço, e $I_{e, t m}$ é o momento de inércia efetivo da treliça mista. Para a treliça isolada, pode-se utilizar a mesma Equação 01, porém substituindo o $I_{e, t m}$ por $I_{e, t i}$.

$\delta_{\text {máx }}=\frac{5 * P_{d} * L^{4}}{384 * E * I_{e, t m}}$

$\mathrm{O}$ valor prescrito para o $I_{e, t m}$ e $I_{e, t i}$ pela norma canadense CAN/CSA-S16-01 [5] e pela norma brasileira NBR 8800 [4] estão mostrados nas equações 02 e 03, respectivamente.

$$
\begin{aligned}
& I_{e, t i}=0,85 * I_{t i} \\
& I_{e, t m}=I_{t m}-0,15 * I_{t i}
\end{aligned}
$$

O momento de inércia da treliça mista, $I_{e, t m}$, é calculado pela redução da área da laje de concreto em uma área de aço equivalente, utilizando o parâmetro $\alpha_{e}$. Na equação (2) $I_{e, t i}$ é o momento de inércia de uma treliça isolada, onde não ocorre a ação mista. Para se levarem em conta as deformações por cisalhamento, a 
norma brasileira NBR 8800 [4] sugere uma redução de 15\% no valor encontrado do momento de inércia da treliça isolada como mostra a equação 02 .

\subsection{Cálculo Analítico e Modelagens Numéricas}

Baseado nas condições dos itens 2.2 e 2.3, um cálculo analítico foi realizado levando à determinação das características estruturais definidas no item 2.1 (veja mais detalhes em TRINDADE [11]). Assim, as seções descritas no item 2.1, foram então usadas como base de entrada para a modelagem elástica e plástica.

A modelagem bi-dimensional, adotando-se comportamento elástico para o aço e o concreto, foi realizada através do software SAP2000 [9] utilizando elementos lineares, onde a conexão entre o banzo superior e a laje foi considerada como sendo de concreto. O momento de inércia referente a essa conexão foi calculado considerando-se uma seção retangular com largura igual ao espaçamento entre conectores e altura igual ao diâmetro do conector stud bolt, porém transformado em concreto, multiplicando o diâmetro pelo parâmetro $\alpha_{e}$. As Figuras 3 e 4 mostram como foram modeladas as treliças isoladas e mistas, respectivamente, pelo software SAP2000.

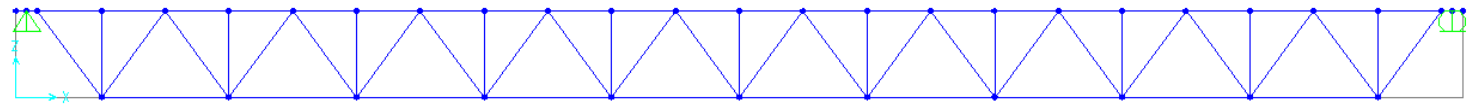

Figura 3: Esquema estático para modelagem da treliça isolada via SAP2000.

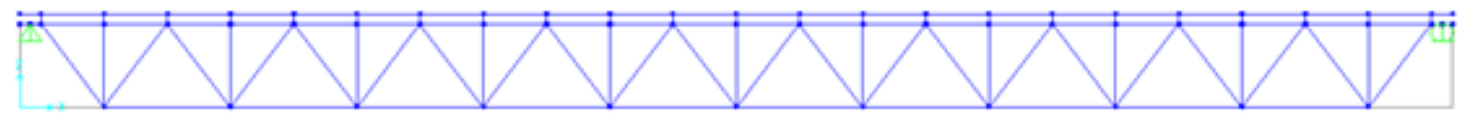

Figura 4: Esquema estático para modelagem da treliça Mista via SAP2000.

A modelagem tri-dimensional foi feita no software ANSYS [2], onde se adotou o elemento Solid185 para modelar a treliça e a laje, enquanto que o elemento BEAM188 foi utilizado para modelar os conectores stud-bolt. O elemento SOLID185 é definido por oito nós, tendo os seguintes três graus de liberdade em cada nó: translações nas direções nodais x, y e z. Esse elemento tem como característica: a plasticidade, hiperelasticidade, grande deflexão, e grande capacidade de deformação. O elemento BEAM188 é apropriado para analisar desde estruturas delgadas a estruturas com relação largura/espessura moderada. $\mathrm{O}$ elemento é baseado na teoria da viga de Timoshenko, que inclui efeitos de cisalhamento e deformação, sendo adequado para análise linear e não-linear com grande rotação e/ou grandes deformações. Ele é um elemento de barra linear, quadrático ou cúbico de dois nós tendo os seguintes 6 graus de liberdade em cada nó: três translações nas direções $\mathrm{X}, \mathrm{Y}$ e Z e três rotações nas direções $\mathrm{X}, \mathrm{Y}$ e Z.

A não linearidade física dos materiais foi considerada construindo o diagrama tensão-deformação do aço e do concreto. Para o aço (Figura 3), utilizado nas barras da treliça, foi considerado o modelo Ansys bilinear, com material do tipo bilinear isotropic hardening (BISO), que representa comportamento elastoplástico com encruamento isótropo. Para o concreto (Figura 4) foi utilizado o modelo Ansys multilinear, com material do tipo multilinear isotropic hardening (MISO), onde se devem fornecer as propriedades como: módulo de elasticidade $\left(1440 \mathrm{kN} / \mathrm{cm}^{2}\right)$, que determina a inclinação da origem, coeficiente de Poisson $(0,2)$ e os pontos de tensão e deformação para a plotagem do diagrama prescrito na NBR 6118 [3].

Para a construção da geometria da treliça mista, foram utilizados, no total, 27 volumes. Devido à análise da não-linearidade geométrica, estes elementos apresentaram ângulo de canto máximo não permitido. Nesses casos, optou-se pela geração livre da malha, obtendo-se elementos tetraédricos para as formas do modelo como: banzos, diagonais e montantes.

Para a treliça, a malha foi gerada de forma livre enquanto a laje teve a sua malha mapeada. A treliça teve o seu banzo superior repartido em 3 partes: uma na região central e outras duas na região dos apoios. A laje foi repartida em 24 volumes, 12 na parte central e o restante nas extremidades, tomando o cuidado para que os pontos nodais da região inferior da laje de coincidissem com os pontos nodais do banzo superior, (Figura 5). Após a da divisão dos volumes, tanto para a laje e a treliça, as malhas foram geradas totalizando 80 mil elementos. 


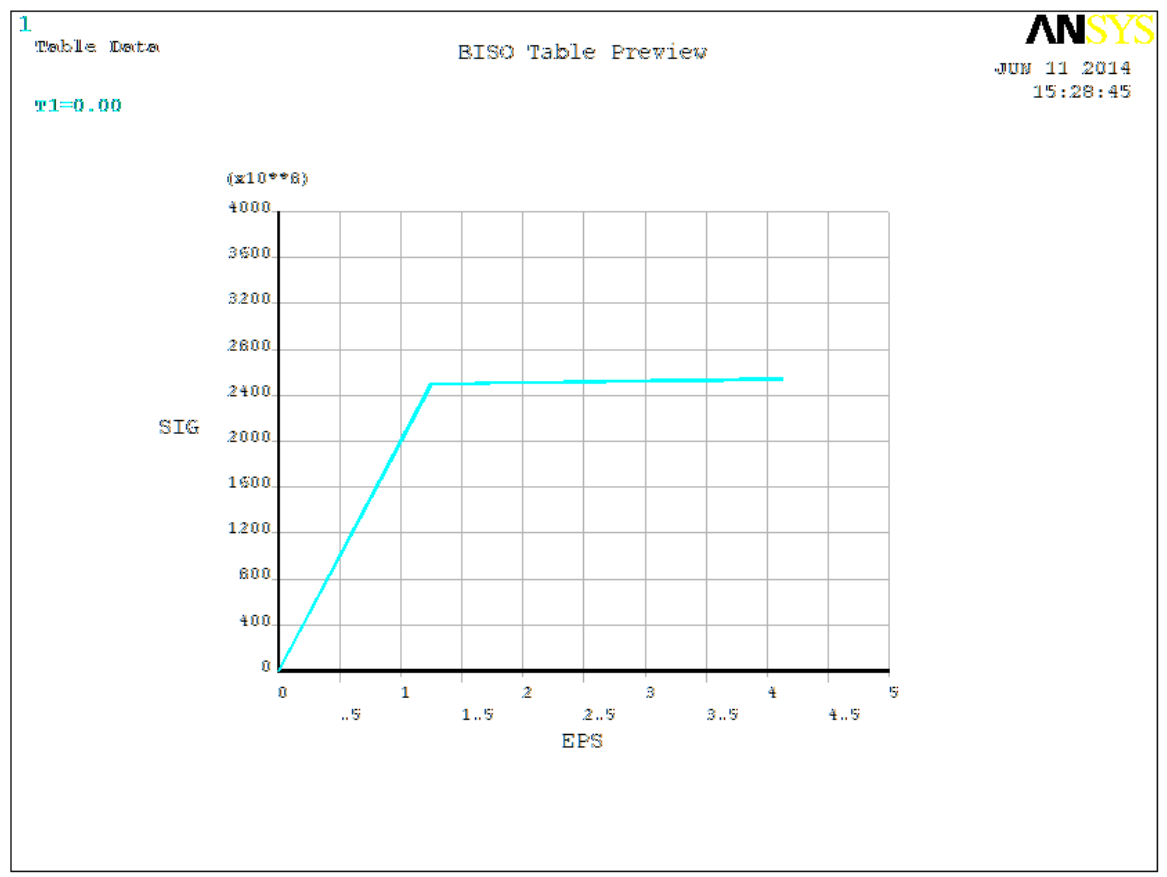

Figura 5: Gráfico Tensão-Deformação para cálculo do módulo de elasticidade tangente.

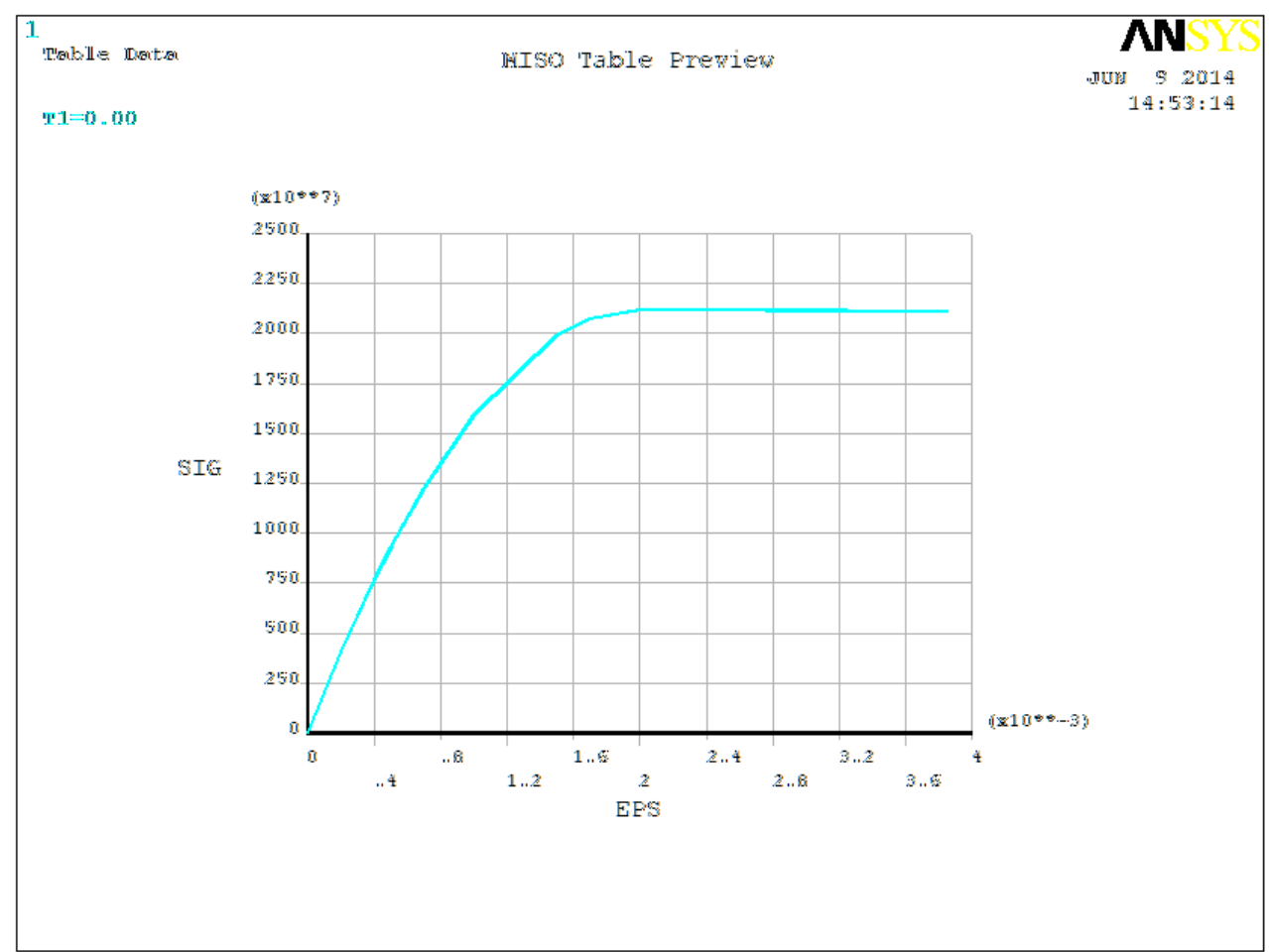

Figura 6: Curva Tensão x Deformação do Concreto. 


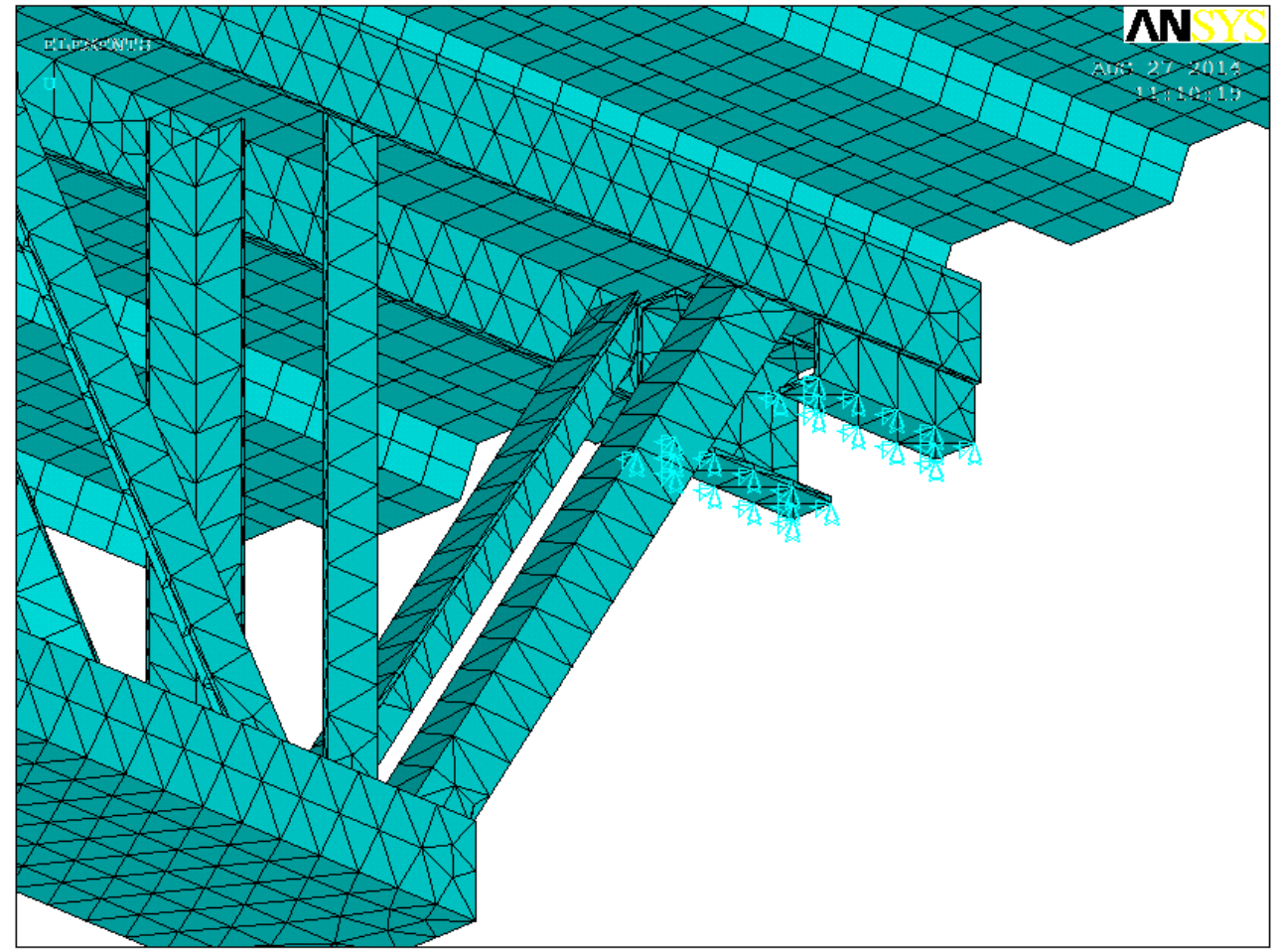

Figura 7: Vista inferior ampliada do apoio da Treliça Mista.

\section{RESULTADOS E DISCUSSÃO}

No que segue, estão os resultados obtidos tanto pelo cálculo analítico, quanto nas modelagens numéricas bidimensionais e tridimensionais. Para as análises bidimensionais, se comparam as resistências de cálculo no Estado Limite Último e os deslocamentos máximos para o Estado Limite de Serviço, utilizando normas nacionais e internacionais. Nas análises tridimensionais se encontram as tensões de Von Mises para o Estado Limite Último e os deslocamentos máximos para o Estado Limite de Serviço.

\subsection{Comportamento estrutural da treliça isolada e da treliça mista para o estado limite último}

A comparação entre os esforços obtidos por cálculo analítico e modelagem elástica via SAP2000 [9], para treliça isolada e mista, está mostrada na Tabela 1 abaixo. A Tabela 1 mostra que os banzos mais carregados são o BI5 e o BS6, enquanto que as diagonais e os montantes mais carregados são a D1 e a M1.

Tabela 1: Comparação de esforços via cálculo analítico e modelagem elástica.

\begin{tabular}{|c|c|c|c|}
\hline BARRA & CÁLCULO ANALÍTICO & MODELAGEM ELÁSTICA & RESISTÊNCIA DE CÁLCULO \\
\hline BI5 & $\mathrm{N}_{\mathrm{t}, \mathrm{Sd}}=533,5 \mathrm{KN}$ & $\mathrm{N}_{\mathrm{t}, \mathrm{Sd}}=494 \mathrm{KN}$ & $\mathrm{N}_{\mathrm{t}, \mathrm{Rd}}=612,73 \mathrm{KN}$ \\
\hline BS6 & $\mathrm{N}_{\mathrm{c}, \mathrm{Sd}}=208 \mathrm{KN}$ & $\mathrm{N}_{\mathrm{c}, \mathrm{Sd}}=199,85 \mathrm{KN}$ & $\mathrm{N}_{\mathrm{c}, \mathrm{Rd}}=532,4$ \\
\hline \multirow{2}{*}{$\mathrm{N} 1$} & $\mathrm{~N}_{\mathrm{t}, \mathrm{dd}}=187 \mathrm{KN}$ & $\mathrm{N}_{\mathrm{t}, \mathrm{Sd}}=192,74 \mathrm{KN}$ & $\mathrm{N}_{\mathrm{t}, \mathrm{Sd}}=199,77$ \\
\hline \multirow{2}{*}{ M1 } & $\mathrm{N}_{\mathrm{c}, \mathrm{Sd}}=136 \mathrm{KN}$ & $\mathrm{N}_{\mathrm{c}, \mathrm{Sd}}=34,62 \mathrm{KN}$ & $\mathrm{N}_{\mathrm{c}, \mathrm{Sd}}=160,15$ \\
\hline \multirow{2}{*}{ conectores } & $\Sigma \mathrm{Q}_{\mathrm{rd}}=962,5 \mathrm{KN}$ & $\Sigma \mathrm{Q}_{\mathrm{sd}}=497 \mathrm{KN}$ & \\
\cline { 2 - 4 } & $\mathrm{Q}_{\mathrm{rd}, \text { max }}=87,5 \mathrm{KN}$ & $\mathrm{Q}_{\mathrm{rd}, \text { máx }}=92,46 \mathrm{KN}$ & \\
\hline
\end{tabular}

Para a análise não linear do software Ansys, foram utilizados os mesmos casos de carregamentos do cálculo analítico e da modelagem elástica e manteve-se a mesma geometria da treliça isolada e mista. As Figuras 6 a 8 mostram as tensões de Von Mises para a treliça mista, onde se percebe a contribuição da laje para a diminuição de tensões no banzo superior da treliça e garantindo a ação mista do sistema. Da mesma forma que a treliça isolada, os apoios acabaram ficando muito carregados, atingindo as tensões de escoamento. 


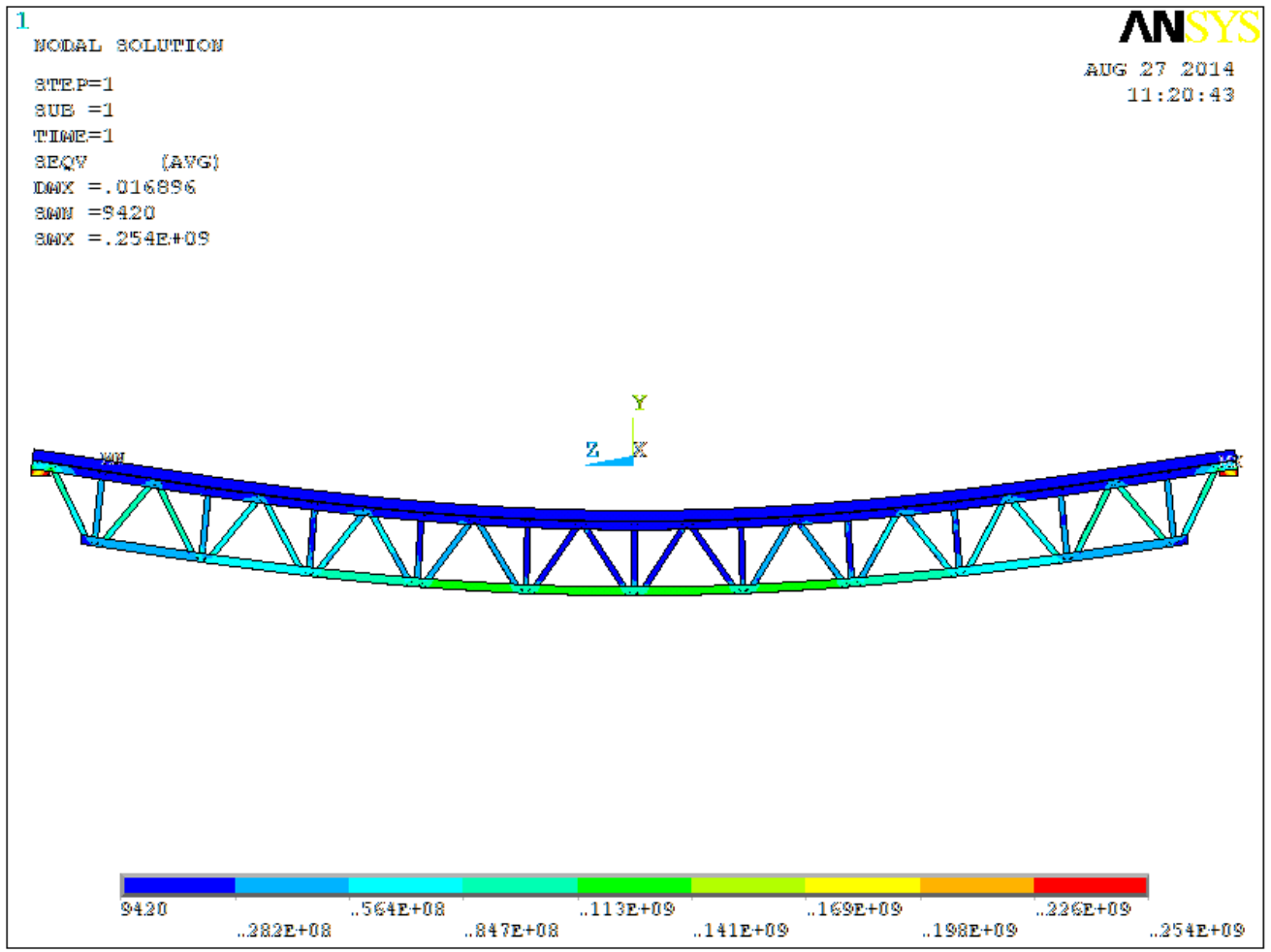

Figura 8: Vista Geral Longitudinal da distribuição de tensões de Von Mises da Treliça Mista.

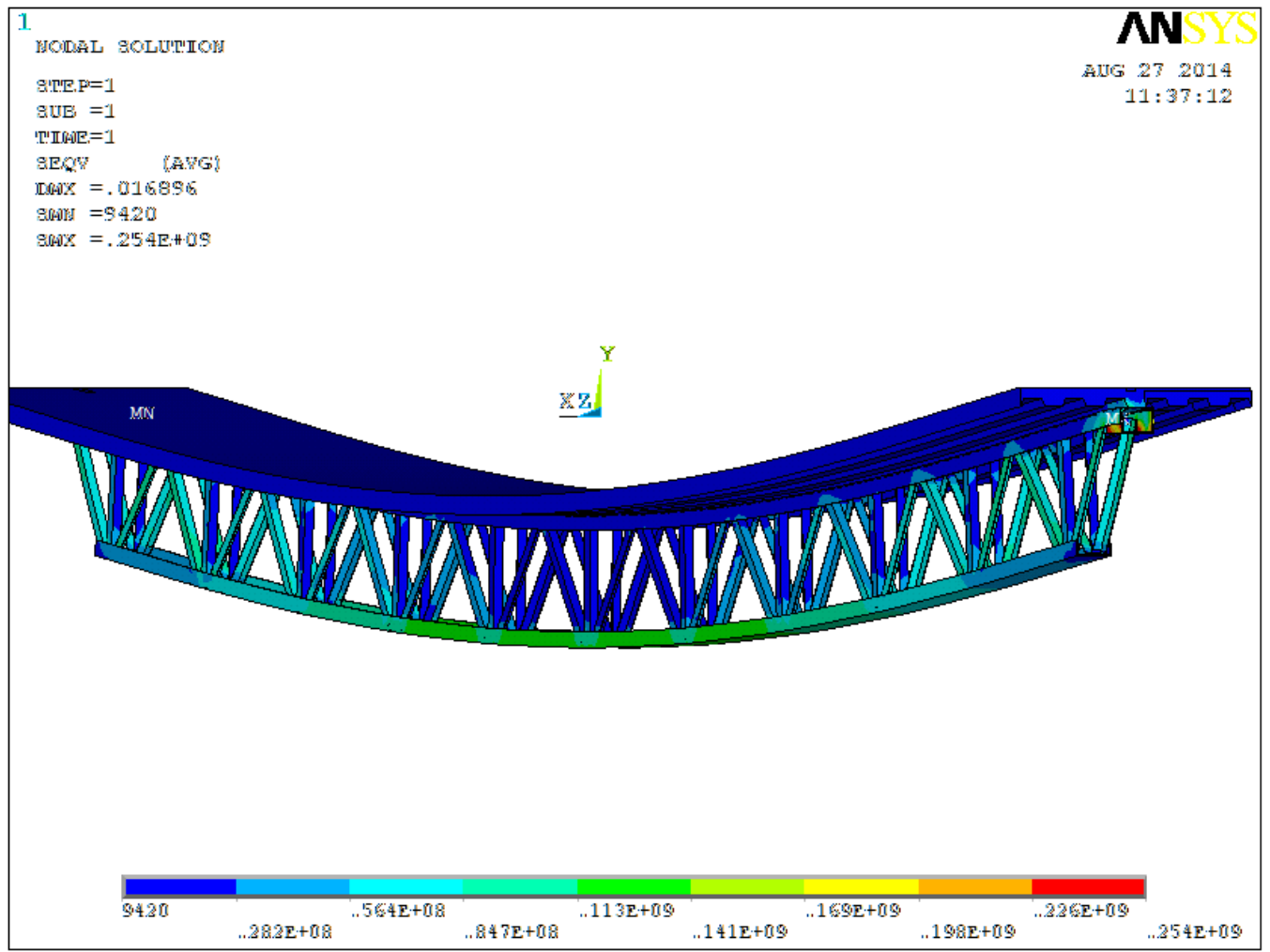

Figura 9: Vista tridimensional da distribuição de Von Mises da Treliça Mista. 


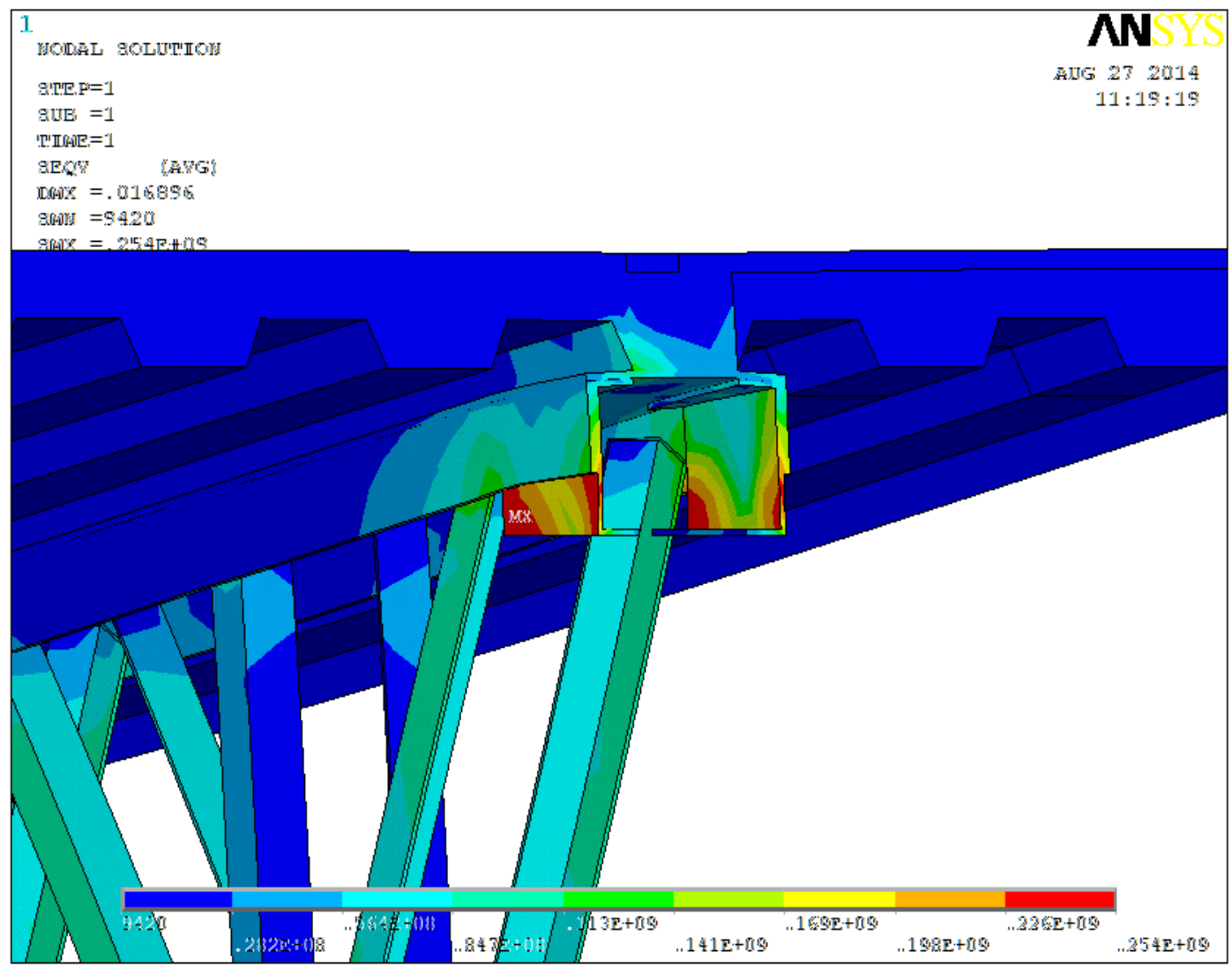

Figura 10: Detalhe da Vista dos apoios e sua distribuição de Von Mises na Treliça Mista.

\subsection{Comportamento estrutural da treliça isolada e da treliça mista para o estado limite de serviço}

Conforme a NBR 8800 [4], Anexo C, o deslocamento máximo permitido para vigas de piso é dado pelo valor do vão dividido por 350 , o que leva a $3,88 \mathrm{~cm}$. A vibração foi verificada em função da frequência natural da treliça mista, que segundo a NBR 8800 [4], Anexo L, tem que ser maior que 4Hz. O deslocamento vertical máximo para a treliça isolada foi calculado pelas expressões de NEAL et al. [8], pelas normas CAN/CSAS16-01 [5], NBR 8800 [4] e por modelagem elástica. O deslocamento vertical máximo para treliça mista foi calculado pelas expressões de NEAL et al. [8], pela ASCE [1], pelas normas CAN/CSA-S16-01 [5], NBR 8800 [4] e por modelagem elástica. A vibração foi verificada por metodologia proposta pelas publicações SCI-P-083 [8], SCI-P-355 [6] e também por modelagem elástica.

Tabela 2: Deslocamento Vertical Máximo obtido por normas nacionais e internacionais.

\begin{tabular}{|c|c|c|}
\hline NORMAS & TRELIÇA ISOLADA & TRELIÇA MISTA \\
\hline NEAL et al & $\delta_{\text {máx }}=1,33 \mathrm{~cm}$ & $\delta_{\text {máx }}=1,05 \mathrm{~cm}$ \\
\hline NBR 8800 & $\delta_{\text {máx }}=1,57 \mathrm{~cm}$ & $\delta_{\text {máx }}=1,13 \mathrm{~cm}$ \\
\hline CAN/CSA-S16-01 & $\delta_{\text {máx }}=1,57 \mathrm{~cm}$ & $\delta_{\text {máx }}=1,13 \mathrm{~cm}$ \\
\hline $\begin{array}{c}\text { ASCE (1996) } \\
\text { SAP2000 [9] } \\
\begin{array}{c}\text { Modelagem Plástica via } \\
\text { ANSYS [2] }\end{array}\end{array}$ & $\delta_{\text {máx }}=1,69 \mathrm{~cm}$ & $\delta_{\text {máx }}=1,21 \mathrm{~cm}$ \\
$\delta_{\text {máx }}=1,68 \mathrm{~cm}$ & $\delta_{\text {máx }}=1,46 \mathrm{~cm}$ \\
\hline
\end{tabular}


A Tabela 2 mostra os deslocamentos verticais máximos obtidos por cálculo, aqueles prescritos por normas nacionais e internacionais e ainda aqueles obtidos por modelagem elástica. A Tabela 3 mostra as frequências naturais descritas em publicações internacionais e aqueles referentes à modelagem elástica.

Tabela 3: Frequências naturais obtidas por publicações internacionais.

\begin{tabular}{|c|c|}
\hline NORMAS & TRELIÇA MISTA \\
\hline Publicação SCI-P-083 & $\mathrm{f}_{\mathrm{n}}=7,00 \mathrm{~Hz}$ \\
\hline Publicação SCI-P-083 & $\mathrm{f}_{\mathrm{n}}=5,33 \mathrm{~Hz}$ \\
\hline Modelagem Elástica & $\mathrm{f}_{\mathrm{n}}=5,60 \mathrm{~Hz}$ \\
\hline
\end{tabular}

As Figuras 11 e 12 mostram a posição onde se encontram os deslocamentos máximos para as treliças isoladas e mistas, respectivamente, via SAP2000. Já as Figuras 13 e 14 mostram a posição onde se encontram os deslocamentos máximos para as treliças isoladas e mistas, respectivamente, via ANSYS.

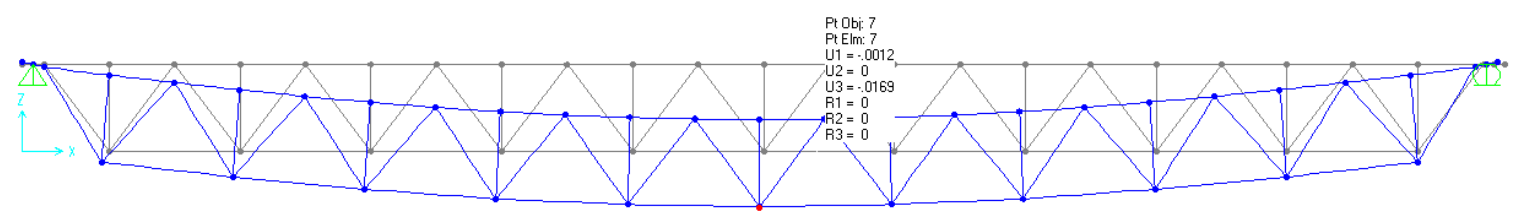

Figura 11: Deslocamento vertical máximo na viga isolada via Software SAP2000.

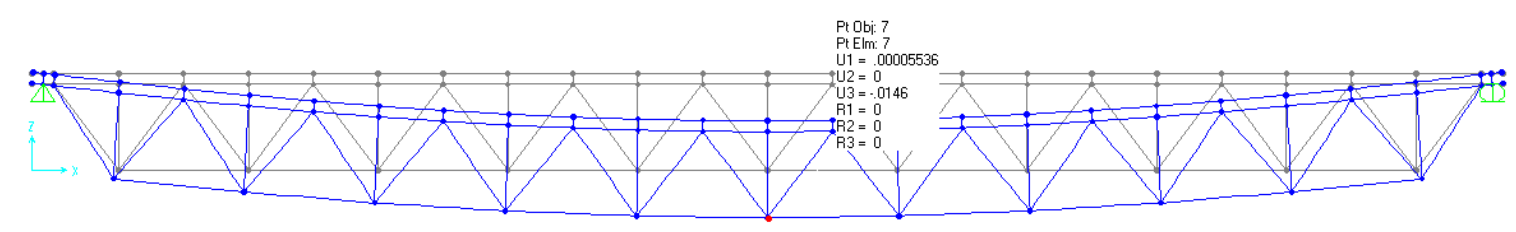

Figura 12: Deslocamento vertical máximo na viga mista via Software SAP2000.

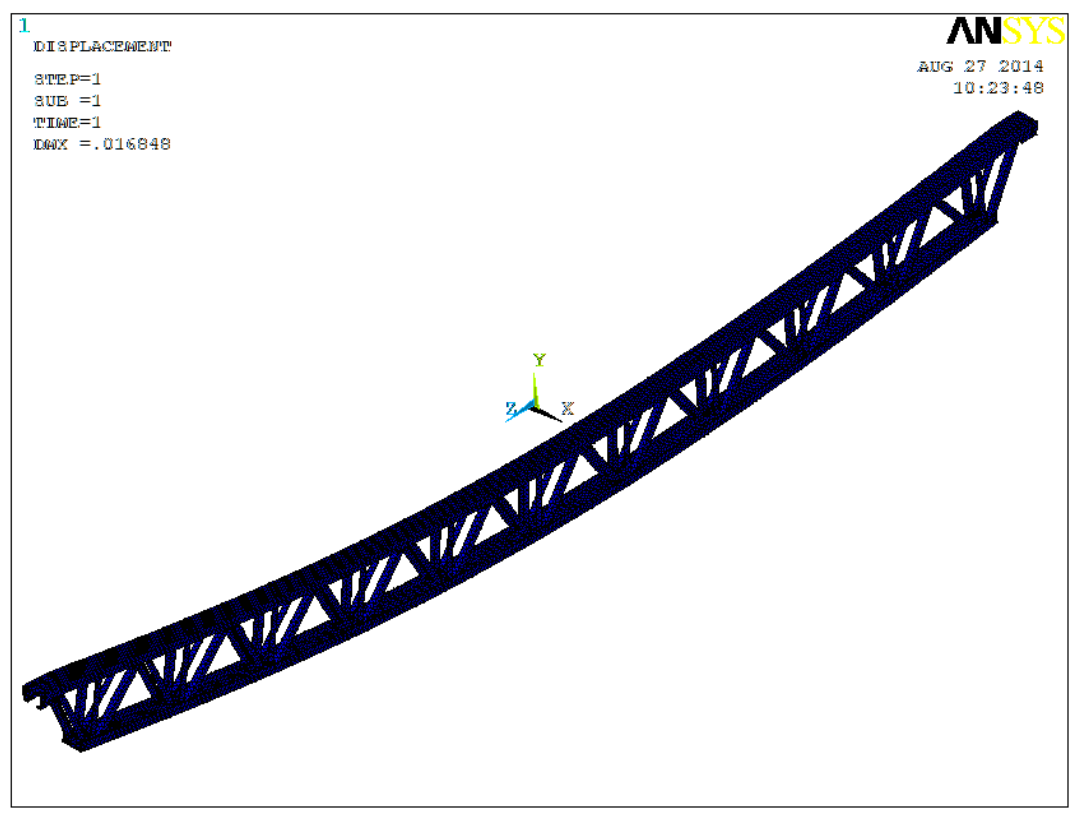

Figura 13: Deslocamento vertical máximo na viga isolada via Software ANSYS. 


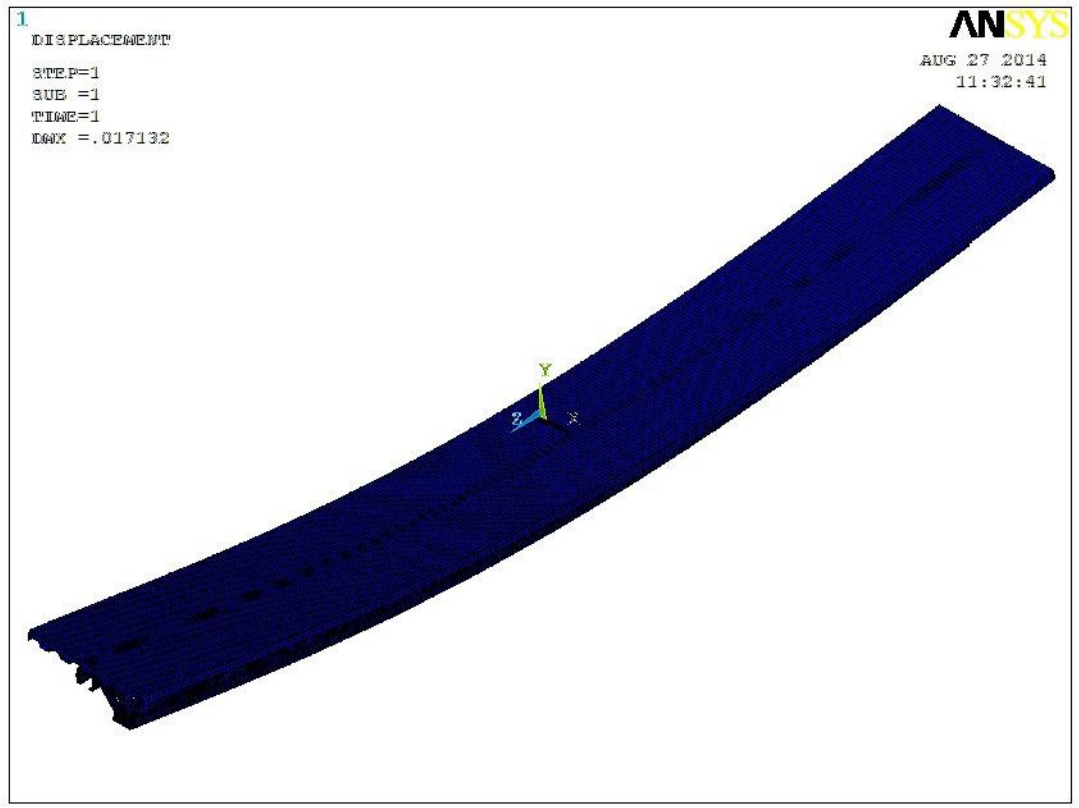

Figura 14: Deslocamento vertical máximo na viga mista via Software ANSYS.

\section{CONCLUSÕES}

O principal objetivo deste trabalho foi avaliar o comportamento de uma treliça steel-joist mista através de análise teórica e numérica. Constatou-se que a escolha do banzo superior é influenciada por relações geométricas entre o diâmetro dos conectores e a espessura e largura plana do perfil do banzo. Estes parâmetros influenciam na resistência de cada conector, que quando atuantes em grupo, são responsáveis pela transferência do cisalhamento horizontal entre a laje e o banzo superior, determinando inclusive se a ligação será parcial ou total.

Os esforços encontrados através de modelagem elástica da viga mista foram utilizados para o dimensionamento do banzo inferior, das diagonais e dos montantes, e, para analisar o comportamento da ligação entre o banzo superior e a laje. O projeto desenvolvido manteve o cisalhamento horizontal nos conectores, e, as resistências da laje, das barras de aço e das ligações entre barras dentro de limites seguros. Mesmo apesar do banzo inferior não ter atingido a tensão de escoamento, devido ao escoamento prematuro dos apoios, a ação mista ocorre porque a somatória das forças cisalhantes nos conectores é maior que o esforço de tração no banzo inferior, o que garante que a ação mista esteja ocorrendo.

Constatou-se ainda, que os perfis das diagonais e montantes na região central da treliça são pouco solicitados, como foi previsto na análise teórica, o que poderia permitir a retirada das diagonais na região central formando um painel Vierendeel. As forças axiais previstas para as diagonais mais solicitadas foram próximas às forças calculadas via modelagem elástica, ao contrário do que ocorreu nas barras do montante. Além disso, a análise através do software ANSYS [2] confirmou a determinação das barras mais solicitadas, observando-se tensões inferiores à tensão de escoamento, como era desejado.

Os valores dos deslocamentos verticais máximos imediatos previstos na análise analítica para treliças isoladas e mistas não se mostraram adequados para serem utilizados em treliças Steel-Joist isoladas e mistas, respectivamente. Isso se deve ao fato de que as modelagens numéricas através dos softwares SAP2000 [9] e ANSYS [2] demonstraram que os deslocamentos são maiores que os valores teóricos e que, portanto, estes métodos teóricos, que são obtidos por normas nacionais e internacionais, não são seguros para serem utilizados para dimensionamento.

\section{AGRADECIMENTOS}

A Coordenação de Aperfeiçoamento de Pessoal de Nível Superior, Capes, pelo suporte financeiro fornecido durante a realização do trabalho. 


\section{BIBLIOGRAFIA}

[1] AMERICAN SOCIETY OF CIVIL ENGINEERS (ASCE). Proposed specification and commentary for composite joists and composite trusses, Journal of Structural Engineering, Reston, v. 122, n. 4, p. 350-358, 1996.

[2] ANSYS INC. Ansys version 12.0 - basic analysis procedure. Houston, PA, United States, 2005.

[3] ASSOCIACAO BRASILEIRA DE NORMAS TECNICAS (ABNT). NBR 6118 - Projeto de estruturas de concreto - Procedimento. Rio de Janeiro: ABNT - Associacao Brasileira de Normas Tecnicas, 2014.

[4] ASSOCIAÇÃO BRASILEIRA DE NORMAS TÉCNICAS- ABNT. NBR 8800 - Projeto de estruturas de aço e de estruturas mistas de aço e concreto de edifícios. Rio da Janeiro, 2008.

[5] CANADIAN STANDARDS ASSOCIATION (CSA).CAN/CSA-S16-1-M89 Limit states design of steel structures, 1989.

[6] LAWSON, R. M., HICKS, S. J. "Design of composite beams with large web openings" - SCI-P-355. The Steel Construction Institute: Ascot, UK, pp. 177-223, 2011.

[7] METFORM, AECWEB, http://www.aecweb.com.br/cls/catalogos/metform/steel_deck_metform[1].pdf. Acessado em Fevereiro de 2014.

[8] NEAL, S., JOHNSON, R., LAWSON, R. M., et al., "Design of composite trusses" - SCI-P-083. Ascot: The Steel Construction Institute, pp. 10-27, 1992.

[9] SAP2000. Sap2000 versão 14.0 - Computer and Strutures,Inc. Multiplus, São Paulo-SP, 1995.

[10] STEEL JOIST INSTITUTE, SJT, https://steeljoist.org/. Acessado em Outubro de 2016.

[11] TRINDADE, L. G. C. Análise estrutural de vigas treliçadas de aço com mesa de concreto. Dissertação de M.Sc, Faculdade de Engenharia de Ilha Solteira, Universidade Estatual Paulista, Ilha Solteira, 2015. 